\title{
Pengaruh Kepemilikan Institusional, Net Profit Margin Dan Debt To Assets Ratio Terhadap Kinerja Keuangan Pada Perusahaan Lq45 Yang Terdaftar Di Bursa Efek Indonesia Periode 2010-2017
}

\author{
Octavianti Purnama \\ Manajemen, Universitas Buddhi Dharma, Indonesia, Banten
}

\begin{abstract}
ABSTRAK
Penelitian ini bertujuan untuk melihat pengaruh dari Kepemilikan Institusional, Net Profit Margin dan Debt to Assets Ratio terhadap Return on Assets. Penelitian ini menggunakan variabel independen berupa Kepemilikan Institusional, Net Profit Margin dan Debt to Assets Ratio. Sedangkan untuk variabel dependennya menggunakan Return on Assets yang dihitung berdasarkan formula ROA.

Populasi yang diambil adalah perusahaan LQ45 yang terdaftar di Bursa Efek Indonesia dan sampel yang didapat adalah empat perusahaan LQ45 yang terdaftar di Bursa Efek Indonesia. Metode analisis yang digunakan berupa analisis regresi linear berganda. Hasil analisis setelah pengujian hipotesis, secara simultan Kepemilikan Institusional, Net Profit Margin dan Debt to Assets Ratio berpengaruh terhadap Return on Assets. Secara parsial terdapat pengaruh dari Kepemilikan Institusional, Net Profit Margin dan Debt to Assets Ratio terhadap Return on Assets.

Kata Kunci : Kepemilikan Institusional, Net Profit Margin, Debt to Assets Ratio, Return on Assets.
\end{abstract}

\begin{abstract}
The writing of this thesis is intended to find out effect of Institutional Ownership, Net Profit Margin and Debt to Assets Ratio on Return on Assets. This research uses independent variable Institutional Ownership, Net Profit Margin and Debt to Assets Ratio. And the dependent variable Return on Assets, calculated by the ROA formula.

The population in this study are LQ45 companies listed in Indonesia Stock Exchange and the sample used in this research is population that is four LQ45 companies listed in Indonesia Stock Exchange. The analysis method used is multiple linear regression analysis. The results of analysis through hypothesis testing, simultaneously Institutional Ownership, Net Profit Margin and Debt to Assets Ratio have significant effect on Return on Assets. Partially, there is a significant influence from Institutional Ownership, Net Profit Margin and Debt to Assets Ratio to Return on Assets Ratio.
\end{abstract}

Keywords : Institutional Ownership, Net Profit Margin, Debt to Assets Ratio, Return on Assets. 


\section{Pendahuluan}

Perkembangan teknologi pada era 2000 -an sangatlah signifikan. Hal ini dapat dilihat dari kemunculan perangkat-perangkat gawai atau teknologi yang semakin canggih dan memudahkan kehidupan manusia. Hal ini mengakibatkan persaingan menjadi semakin ketat di antara perusahan-perusahaan. Untuk meningkatkan posisi persaingan suatu perusahaan, perusahaan harus meningkatkan kinerja keuangan yang dimilikinya. Dengan kinerja keuangan yang baik, para investor juga bisa tertarik untuk menanamkan modalnya di perusahaan tersebut. Dengan demikian, perusahaan dapat menumbuhkan perusahaannya dan mengalahkan pesaingpesaingnya. Untuk meningkatkan posisi persaingan suatu perusahaan, perusahaan harus meningkatkan kinerja keuangan yang dimilikinya. Dengan kinerja keuangan yang baik, para investor juga bisa tertarik untuk menanamkan modalnya di perusahaan tersebut. Dengan demikian, perusahaan dapat menumbuhkan perusahaannya dan mengalahkan pesaing-pesaingnya.

Salah satu cara untuk melihat kinerja keuangan adalah dengan melihat rasio Return on Assets. Menurut (Husnan \& Pudjiastuti, 2015, p. 103) ROA merupakan rasio yang digunakan untuk menilai seberapa besar kemampuan total aset yang dimiliki perusahaan dapat menciptakan laba bersih setelah pajak bagi perusahaan. Ketidakpastian rasio ini menurut Husnan adalah tidak semua aset dibiayai oleh kas perusahaan. Sebagian atau lebih mungkin dibiayai oleh utang. Walau demikian, investor kerap kali menggunakan ROA sebagai dasar dalam melihat apakah perusahaan tersebut bertumbuh atau tidak.

Ada beberapa faktor yang memengaruhi naik turunnya kinerja keuangan. Menurut Jensen dan Meckling (1976) dalam (Epi, 2017, pp. 1-2) salah satu faktor yang memegang peranan dalam naik turunnya kinerja keuangan suatu perusahaan adalah struktur kepemilikan.

Struktur kepemilikan sendiri dapat diartikan sebagai sebuah mekanisme yang digunakan dengan tujuan mengurangi masalah antara manajer, pihak-pihak internal perusahaan dengan pemegang saham seperti investor.

Salah satu bagian dari struktur kepemilikan adalah kepemilikan isntitusional. Kepemilikan institusional adalah kepemilikan saham oleh pemerintah, institusi keuangan, institusi berbadan hukum, institusi luar negeri, dana perwalian, dan institusi lainnya pada akhir tahun. Adanya kepemilikan institusional di suatu perusahaan akan mendorong peningkatan pengawasan agar lebih optimal terhadap kekuasaan yang dapat digunakan untuk mendukung atau sebaliknya terhadap kinerja manajemen. Pengawasan yang dilakukan oleh investor institusional sangat bergantung pada besarnya investasi yang dilakukan. (Subagyo, Masruroh, \& Bastian, 2018, p. 47)

Disamping itu, faktor lain yang memengaruhi kinerja keuangan adalah Net Profit Margin (NPM). NPM digunakan untuk mengukur berapa banyak laba operasi (EBIT) dihasilkan dari setiap rupiah penjualan (Husnan \& Pudjiastuti, 2015, p. 78). Penjualan sangatlah penting karena dengan meningkatnya penjualan maka semakin 
banyak pula laba yang bisa diraih dan kinerja keuangan pada saatnya juga akan meningkat. Hal ini selaras dengan penelitian Antasari.

Kemudian dilihat dari sisi utang, Debt to Assets (DAR) juga diduga memiliki peranan kuat dalam naik turunnya kinerja keuangan. DAR sendiri digunakan untuk melihat seberapa banyak aset perusahaan yang dibiayai oleh utang, - baik utang jangka pendek atau panjang. (Harlow, 2014, p. 126)

\section{Landasan Teori}

\section{Shareholder Theory dan teori pemegang saham}

Shareholder Theory diperkenalkan oleh Edward Freeman pada tahun 1988. Menurut teori ini, shareholder memiliki ruang lingkup yang sangat besar, mereka adalah pemegang saham, karyawan, pemasok, pelanggan, masyarakat setempat, lingkungan, serta masyarakat dunia. Oleh karena itu sudah menjadi tugas bagi pemegang saham untuk menjaga keseimbangan antara semua elemen yang ada agar tidak terjadi kontradiksi.

Hal itu berbeda dengan teori pemegang saham yang diperkenalkan oleh Milton Friedman pada tahun 1970 pada New York Times. Menurut Friedman, hanya ada satu tugas dari tanggung jawab sosial, yaitu menciptakan keuntungan sebesarbesarnya bagi perusahaan dengan menggunakan sumber daya yang ada tanpa melanggar aturan dalam regulasi, transparan serta tanpa penipuan. Idenya adalah dengan meningkatkan nilai pemegang saham tanpa melanggar nilai sosial dan aturan. (Kurniawan \& Budhi, 2017, p. 374)

\section{Teori Keagenan}

Menurut (Supriyono, 2018, p. 63) teori keagenan mendeskripsikan hubungan antara prinsipal dan agen. Prinsipal diibaratkan sebagai pemegang saham dan agen diibaratkan sebagai manajer. Prinsipal kerap kali memiliki tujuan yang berbeda dengan manajer. Mereka berdua memiliki konsep yang berbeda. Oleh karena itu, terjadilah kontradiksi antara tujuan manajer dan tujuan pemegang saham. Diharapkan pendelegasian wewenang dapat menyelaraskan keagenan dan hubungan antara prinsipal dengan agen. Selain itu teori keagenan juga mengurangi tindakan-tindakan agen yang di luar kendali prinsipal, menggantikan zero-sum games menjadi solusi plus-sum games sehingga menjamin kemakmuran prinsipal dan agen.

\section{Kepemilikan Institusional}

Struktur kepemilikan sendiri adalah sebuah mekanisme yang digunakan untuk mengurangi masalah antara manajer; pihak-pihak internal perusahaan dengan pemegang saham seperti investor. (Subagyo, Masruroh, \& Bastian, 2018, p. 47)

Menurut (Hery, 2014, hal. 172) kepemilikan institusional menggambarkan tingkat saham atau kepemilikan yang dimiliki oleh institusi-institusi. Institusi dapat berupa institusi keuangan seperti bank, asuransi, dana pensiun dan asset management.

Penelitian yang dilakukan oleh Hermiyetti dan Erlinda Katlantis (2016) menyatakan bahwa kepemilikan institusional memiliki pengaruh yang kuat dalam kinerja keuangan suatu perusahaan. Dapat dilihat bahwa berarti ada kepentingan antara prinsipal dan agen dalam kinerja keuangan suatu perusahaan. 


\section{Net Profit Margin}

Menurut (Sutrisno, 2017, p. 212) Profit Margin adalah persentase kemampuan perusahaan dalam menciptakan laba/keuntungan dibandingkan dengan penjualan yang telah dicapai.

Menurut Joel G. Siegel dan Jae K. Shim dalam (Fahmi, 2016, p. 81) Margin laba bersih sama dengan laba bersih dibagi dengan penjualan bersih. Ini menunjukkan kestabilan kesatuan untuk menghasilkan perolehan pada tingkat penjualan khusus. Dengan memeriksa margin laba dan norma industri sebuah perusahaan pada tahuntahun sebelumnya, kita dapat menilai efisiensi operasi dan strategi penetapan harga serta status persaingan perusahaan dengan perusahaan lain dalam industri tersebut.

\section{Debt To Assets Ratio}

Menurut (Sutrisno, 2017, p. 208) rasio debt to assets adalah rasio yang digunakan untuk mengukur persentase dari aktiva atau aset perusahaan yang didanai oleh utang. Investor lebih menyukai perusahaan dengan persentase DAR yang kecil karena mereka mereka menganggap dana yang ditanamkannya akan lebih aman.

Menurut (Kasmir, 2016, p. 109) Debt Ratio merupakan rasio utang yang digunakan untuk mengukur seberapa besar aktiva perusahaan dibiayai oleh utang atau seberapa besar utang perusahaan berpengaruh terhadap pengelolaan aktiva.

\section{Return On Assets}

Return on Assets / Return on Investment adalah sebuah perhitungan rasio yang melihat seberapa jauh keuntungan dari pada investasi yang telah ditempatkan pada suatu usaha. Seringkali dikaitkan dengan aset karena sejenis (Fahmi, 2016, p. 80). Sedangkan menurut (Sutrisno, 2017, p. 213) ROA atau rentabilitas ekonomis merupakan ukuran kemampuan perusahaan dalam menghasilkan laba dengan semua aktiva yang dimiliki oleh perusahaan.

Selanjutnya menurut (Kasmir, 2016, p. 115) ROA atau ROI merupakan rasio yang menunjukkan hasil (return) atas jumlah aktiva yang digunakan dalam perusahaan.

ROA juga dinilai sebagai suatu ukuran tentang bagaimana efektivitas manajemen suatu perusahaan dalam mengelola aktiva dan investasinya.

\section{Perumusan Hipotesis}

\section{Pengaruh Kepemilikan Institusional Terhadap Return on Assets}

Kepemilikan Institusional merupakan salah satu variabel dalam Good Corporate Governance. Kepemilikan Institusional sendiri menurut (Ayuningtias, 2013) dalam (Hery, 2017, p. 30) adalah persentase kepemilikan saham yang dimiliki oleh institusi di luar perusahaan, seperti perusahaan asuransi, dana pensiun dan institusi lainnya. (Crutchley dan Hansen, 1999) dalam (Wahyudi dan Pawestri, 2005) dalam (Rachman, 2014) menyimpulkan bahwa kepemilikan institusional yang tinggi dapat digunakan untuk mengurangi masalah keagenan. Semakin tinggi kepemilikan institusional maka semakin kuat kontrol eksternal terhadap perusahaan dan 
mengurangi biaya keagenan sehinga perusahaan akan menggunakan dividen yang rendah.

Dengan rendahnya biaya maka kinerja keuangan juga akan semakin meningkat karena laba yang didapat semakin banyak. Disamping itu dengan adanya kepemilikan institusional yang tinggi maka akan semakin tinggi pula pengawasan pihak luar terhadap manajer perusahaan sehingga keputusan manajer akan lebih diawasi dan terorganisir sehingga tidak ada pihak yang merasa keputusan manajer diambil secara sepihak.

H1: Kepemilikan Institusional memiliki pengaruh yang signifikan terhadap Return on Assets pada perusahaan LQ45 yang terdaftar pada Bursa Efek Indonesia periode 2010-2017.

Pengaruh Net Profit Margin Terhadap Return on Assets

Net Profit Margin adalah perbandingan antara laba bersih yang telah dikurangi oleh pajak dan biaya yang dibandingkan dengan penjualan bersih atau pendapatan. Rasio ini menunjukkan bahwa dengan semakin meningkatnya NPM, maka berarti semakin tinggi pula laba yang dihasilkan dan semakin tinggi pula pendapatan yang pada akhirannya akan memengaruhi kinerja keuangan perusahaan.

H2: Net Profit Margin memiliki pengaruh yang signifikan terhadap Return on Assets pada perusahaan LQ45 yang terdaftar pada Bursa Efek Indonesia periode 2010-2017

\section{Pengaruh Debt to Assets Terhadap Return on Assets}

Debt to Assets adalah perbandingan antara total utang dengan total aset yang dimiliki perusahaan. Semakin rendah DAR maka semakin kecil utang yang dimiliki perusahaan atau aktiva yang dimiliki perusahaan tidak lagi dibiayai oleh utang. Dengan demikian maka laba yang dimiliki perusahaan tentu akan lebih besar karena mereka tidak perlu membayar utang lagi, sehingga kinerja keuangan akan meningkat.

H3: Debt to Assets Ratio memiliki pengaruh yang signifikan terhadap Return on Assets pada perusahaan LQ45 yang terdaftar pada Bursa Efek Indonesia periode 2010-2017.

Sedangkan secara simultan, hipotesisnya dapat dirumuskan sebagai berikut:

$\mathrm{H}_{4}$ : Kepemilikan Institusional, Net Profit Margin, dan Debt to Assets Ratio memiliki pengaruh yang signifikan secara bersama-sama terhadap Return on Assets pada perusahaan LQ45 yang terdaftar pada Bursa Efek Indonesia periode 2010-2017.

\section{Metode Penelitian}

\section{Sampel dan Data}

Populasi yang digunakan dalam penelitian ini adalah perusahaan LQ45 yang terdaftar di Bursa Efek Indonesia periode 2010-2017, sedangkan untuk pemilihan sampel sendiri menggunakan teknik purposive sampling, yaitu sampel yang memiliki kriteria sebagai berikut:

1. Perusahaan yang terdaftar di BEI yang masuk LQ45 selama tahun 2010-2017.

2. Perusahaan yang masuk dalam 5 besar dari tahun 2010-2017

3. Perusahaan yang bukan bank dan real estate. 
4. Perusahaan yang tidak mengalami kerugian.

\section{Model Penelitian}

Penelitian ini bertujuan untuk melihat pengaruh kepemilikan institusional, net profit marign dan debt to assets ratio terhadap kinerja keuangan yang diproksikan dengan return on assets. Untuk membuktikan hipotesis-hipotesis yang diajukan dalam penelitian ini, maka model regresi penelitian adalah sebagai berikut:

$$
\mathrm{Y}=\alpha+\beta 1 \times 1+\beta 2 \times 2+\beta 3 \times 3+\varepsilon
$$

Keterangan :

$\mathrm{Y}=$ Return on assets

B1= Beta variabel kepemilikan institusional

X1 = Kepemilikan institusional

B2 = Beta variabel net profit margin

$\mathrm{X} 2=$ Net profit margin

$\mathrm{B} 3=$ Beta variabel debt to assets ratio

$\mathrm{X} 3=$ Debt to assets ratio

$\mathrm{Ei}=$ Error

$\mathrm{KI}=\frac{\text { Jumlah Saham Institusional }}{\text { Jumlah Saham Beredar }}$

Debt to Assets Ratio (DAR)

$\mathrm{DAR}=\frac{\text { Total Debt }}{\text { TOTAL Assets }} \times 100 \%$

Net Profit Margin (NPM)

$\mathrm{NPM}=\frac{\text { Net Income }}{\text { Net Sales }} x 100 \%$

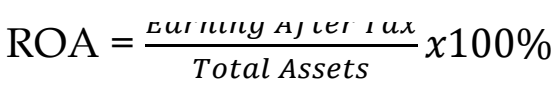

\section{Hasil Penelitian Dan Pembahasan}

Uji Asumsi Klasik

Uji Normalitas

Tabel 1 Tabel Normalitas

One-Sample Kolmogorov-Smirnov Test

\begin{tabular}{|c|c|c|}
\hline & & $\begin{array}{l}\text { Unstandardiz } \\
\text { ed Residual }\end{array}$ \\
\hline$N$ & & 32 \\
\hline \multirow[t]{2}{*}{ Normal Parameters ${ }^{a, b}$} & Mean & .0000000 \\
\hline & Std. Deviation & 3.34292620 \\
\hline \multirow[t]{3}{*}{ Most Extreme Differences } & Absolute & .130 \\
\hline & Positive & .130 \\
\hline & Negative & -.066 \\
\hline Kolmogorov-Smirnov Z & & .734 \\
\hline Asymp. Sig. (2-tailed) & & .653 \\
\hline
\end{tabular}

a. Test distribution is Normal.

b. Calculated from data. 


\section{Sumber : Hasil uji SPSS 21}

Berdasarkan tabel Kolgomorov-Smirnov dapat disimpulkan bahwa model regresi bersifat normal dan layak digunakan dalam penelitian. Dapat dilihat dari nilai asymp. Sig (2-tailed) yang lebih dari 0.05 atau sebesar 0.653 .

\section{Tabel 2 Tabel Multikolonieritas}

Coefficients $^{a}$

\begin{tabular}{|l|r|r|}
\hline \multirow{2}{*}{ Model } & \multicolumn{2}{|c|}{ Collinearity Statistics } \\
\cline { 2 - 3 } & Tolerance & \multicolumn{1}{c|}{ VIF } \\
\hline & .526 & 1.900 \\
& .326 & 3.068 \\
& .223 & 4.491 \\
\hline
\end{tabular}

a. Dependent Variable: roa

\section{Sumber : Hasil uji SPSS 21}

Berdasarkan tabel perhitungan uji SPSS di atas, dapat dilihat bahwa variabel institusional memiliki nilai tolerance sebesar 0.526 dengan nilai VIF 1.900 yang artinya tidak ada multikolonieritas. NPM memiliki nilai tolerance sebesar 0.326 dengan nilai VIF sebesar 3.068 yang artinya tidak ada multikolonieritas. Untuk variabel DAR, nilai tolerance yang dimilikinya sebesar 0.223 dan nilai VIFnya adalah 4.491 sehingga dapat disimpulkan bahwa semua variabel independen tidak terjadi multikolonieritas.

\section{Uji Heteroskedastisitas}

\section{Gambar 1 Uji Heteroskedastisitas}

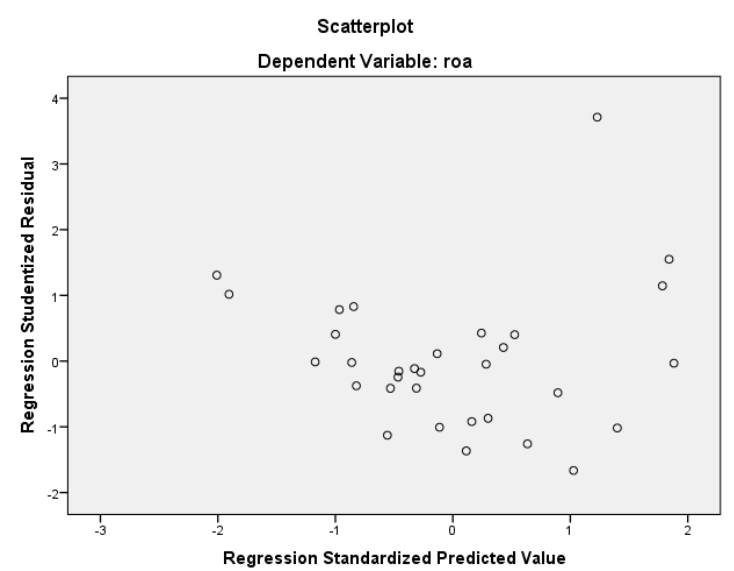

\section{Sumber : Hasil uji SPSS 21}

Dari gambar scatterplot di atas, dapat di lihat bahwa titik-titik menyebar secara baik dan tidak saling menumpuk sehingga dapat disimpulkan bahwa tidak terjadi heteroskedastisitas sehingga model regresi layak untuk memprediksi Return on Assets (ROA) dengan masukan Kepemilikan Institusional, Net Profit Margin (NPM) dan Debt to Assets (DAR) sebagai variabel independen. 


\section{Uji Autokorelasi}

\section{Tabel 3 Tabel Autokorelasi}

\section{Model Summary}

\begin{tabular}{|l|l|r|r|r|r|}
\hline Model & $\mathrm{R}$ & R Square & $\begin{array}{c}\text { Adjusted R } \\
\text { Square }\end{array}$ & $\begin{array}{c}\text { Std. Error of } \\
\text { the Estimate }\end{array}$ & $\begin{array}{c}\text { Durbin- } \\
\text { Watson }\end{array}$ \\
\hline 1 & $.850^{\mathrm{a}}$ & .723 & .693 & 3.51746 & 1.416 \\
\hline
\end{tabular}

a. Predictors: (Constant), dar, institusional, npm

b. Dependent Variable: roa

\section{Sumber : Hasil uji SPSS 21}

Berdasarkan tabel di atas, diketahui bahwa nilai Durbin Watson sebesar 1.416 dengan nilai tabel menggunakan signifikansi 5\% dengan jumlah sampel 32 dan dengan jumlah variabel independen $(\mathrm{k}=3)$ maka nilai tabel Durbin Watson untuk $\mathrm{dL}$ $=1.2437$ dan $\mathrm{dU}=1.6505$. Perhitungan autokorelasi sebagai berikut:

$\mathrm{dU}=1.6505$

$\mathrm{dW}=1.416$

$4-\mathrm{dU}=4-1.416=2.584$

Karena hasil dW lebih kecil dari du dan kurang dari 4-dU maka dapat disimpulkan bahwa terjadi autokorelasi di perhitungan SPSS. Oleh karena itu digunakan metode Cochrane Orcutt. Berikut hasil analisis data sesudah transformasi:

Tabel 4 Tabel Autokorelasi Setelah Transformasi

Model Summary

\begin{tabular}{|l|l|r|r|r|r|}
\hline Model & $\mathrm{R}$ & R Square & $\begin{array}{c}\text { Adjusted R } \\
\text { Square }\end{array}$ & $\begin{array}{c}\text { Std. Error of } \\
\text { the Estimate }\end{array}$ & $\begin{array}{c}\text { Durbin- } \\
\text { Watson }\end{array}$ \\
\hline 1 & $.279^{\mathrm{a}}$ & .078 & .046 & 3.25465150 & 1.948 \\
\hline
\end{tabular}

a. Predictors: (Constant), lag_e

b. Dependent Variable: Unstandardized Residual

\section{Sumber : Hasil uji SPSS 21}

Berdasarkan tabel di atas diketahui bahwa nilai Durbin Watson sebesar 1.948. Dengan menggunakan tabel yang memiliki signifikansi 5\% dan jumlah data 32 dengan menggunakan variabel independen $(k=2)$ maka didapatkan nilai dU sebesar 1.6505. Perhitungan autokorelasi adalah sebagai berikut:

$\mathrm{dU}=1.6505$

$\mathrm{DW}=1.948$

$4-\mathrm{dU}=4-1.948=2.052$

Hasil tersebut menunjukkan bahwa DW lebih besar dari du (1.6505) dan lebih kecil dari 2.052 (4-dU). Maka dapat disimpulkan bahwa tidak terjadi autokorelasi. $(1.6505<1.948<2.052)$ 


\section{Analisis Regresi Berganda}

Tabel 5 Tabel Analisis Regresi Berganda

Coefficients $^{a}$

\begin{tabular}{|c|c|c|c|c|c|c|c|c|}
\hline \multirow{2}{*}{\multicolumn{2}{|c|}{ Model }} & \multicolumn{2}{|c|}{ Unstandardized Coefficients } & \multirow{2}{*}{$\begin{array}{c}\text { Standardized } \\
\text { Coefficients } \\
\text { Beta }\end{array}$} & \multirow[b]{2}{*}{$\mathrm{t}$} & \multirow[b]{2}{*}{ Sig. } & \multicolumn{2}{|c|}{ Collinearity Statistics } \\
\hline & & $\mathrm{B}$ & Std. Error & & & & Tolerance & VIF \\
\hline \multirow{3}{*}{1} & institusional & .231 & .063 & .501 & 3.648 & .001 & .526 & 1.900 \\
\hline & $\mathrm{npm}$ & 1.358 & .200 & 1.185 & 6.799 & .000 & .326 & 3.068 \\
\hline & dar & .404 & .105 & .809 & 3.837 & .001 & .223 & 4.491 \\
\hline
\end{tabular}

a. Dependent Variable: roa

\section{Sumber : Hasil uji SPSS 21}

Persamaan regresi yang digunakan adalah

sebagai berikut :

$\mathrm{ROA}=-37.298+0.231 \mathrm{KI}+1.358 \mathrm{NPM}+0.404 \mathrm{DAR}+\varepsilon$

Keterangan :

$\mathrm{ROA}=$ Return on Assets $(\mathrm{Y})$

$\mathrm{KI} \quad=$ Kepemilikan Institusional (X1)

NPM $=$ Net Profit Margin (X2)

$\mathrm{DAR}=$ Debt to Assets Ratio (X3)

$\varepsilon \quad=$ error

Dari hasil uji statistik $\mathrm{t}$ dan persamaan regresi linier berganda, dapat dijelaskan beberapa hal antara lain :

a. Nilai konstanta -37298 menunjukkan bahwa jika KI, NPM, dan DAR bernilai nol, maka ROA sebesar nilai konstanta yaitu -37.298 satuan.

b. Nilai koefisien KI sebesar 0.231 menunjukkan bahwa apabila terdapat kenaikan sebesar 1 satuan pada variabel KI maka koefisien KI akan menaikkan ROA sebesar 0.231 satuan.

Oleh karena itu, KI berpengaruh positif terhadap ROA pada perusahaan LQ45 yang terdaftar di Bursa Efek Indonesia periode 2010-2017.

c. Nilai koefisien NPM sebesar 1.358 menunjukkan bahwa apabila terdapat kenaikan sebesar 1 satuan pada variabel NPM maka keofisien NPM akan meningkatkan ROA sebesar 1.358. Oleh karena itu, NPM berpengaruh positif terhadap ROA pada perusahaan LQ45 yang terdaftar di Bursa Efek Indonesia periode 2010-2017.

d. Nilai koefisien DAR sebesar 0.404 menunjukkan bahwa apabila terdapat kenaikan sebesar 1 satuan pada variabel DAR maka koefisien DAR akan meningkatkan ROA sebesar 0.404. Oleh karena itu, DAR berpengaruh positif terhadap ROA, pada perusahaan LQ45 yang terdaftar di Bursa Efek Indonesia periode 2010-2017.

\section{Uji Parsial (Uji Statistik t)}

Berdasarkan hasil uji SPSS dapat dilihat bahwa secara parsial kepemilikan institusional, net profit margin dan debt to assets ratio berpengaruh signifikan terhadap return on assets karena sig yang dimiliki kurang dari 0.05 . 


\section{Uji ANOVA (Uji Statistif f)}

Tabel 6 Tabel ANOVA

ANOVA $^{\mathrm{a}}$

\begin{tabular}{|c|c|c|c|c|c|c|}
\hline \multicolumn{3}{|c|}{ Sumber:Hasiluji_SPSS 21} & \multirow[b]{2}{*}{ df } & \multirow[b]{2}{*}{ Mean Square } & \multirow[b]{2}{*}{$\mathrm{F}$} & \\
\hline & & $\begin{array}{l}\text { Sum of } \\
\text { Squares }\end{array}$ & & & & Sig. \\
\hline \multirow[t]{3}{*}{1} & Regression & 902.263 & 3 & 300.754 & 24.308 & $.000^{\mathrm{b}}$ \\
\hline & Residual & 346.430 & 28 & 12.372 & & \\
\hline & Total & 1248.693 & 31 & & & \\
\hline
\end{tabular}

a. Dependent Variable: roa

b. Predictors: (Constant), dar, institusional, npm

Berdasarkan tabel di atas maka dapat disimpulkan bahwa secara simultan kepemilikan institusional, net profit margin dan debt to assets ratio berpengaruh terhadap return on assets.

Uji Koefisien Determinasi (Uji Adjusted $R^{2}$ )

Tabel 7 Tabel Uji Koefisien Determinasi

Model Summary ${ }^{\mathrm{b}}$

\begin{tabular}{|l|l|r|r|r|r|}
\hline Model & $\mathrm{R}$ & R Square & $\begin{array}{c}\text { Adjusted R } \\
\text { Square }\end{array}$ & $\begin{array}{c}\text { Std. Error of } \\
\text { the Estimate }\end{array}$ & $\begin{array}{c}\text { Durbin- } \\
\text { Watson }\end{array}$ \\
\hline 1 & $.850^{\mathrm{a}}$ & .723 & .693 & 3.51746 & 1.416 \\
\hline
\end{tabular}

a. Predictors: (Constant), dar, institusional, npm

b. Dependent Variable: roa

\section{Sumber : Hasil uji SPSS 21}

Berdasarkan tabel di atas dapat dilihat bahwa besarnya Adjusted $\mathrm{R}^{2}$ adalah seebsar 0.693. Hal ini berarti variabel ROA dapat dijelaskan oleh variasi dari ketiga variabel independen (Kepemilikan Institusional, NPM, DAR). Sedangkan sisanya, 30.7\% dijelaskan oleh sebab-sebab lain di luar dari model.

\section{Kesimpulan}

Penelitian ini berusaha melihat pengaruh kepemilikan institusional, net profit margin dan debt to assets ratio terhadap kinerja keuangan yang diproksikan dengan return on assets. Berdasarkan penelitian yang dilakukan kepemilikan institusional berpengaruh positif signifikan terhadap return on assets. Net profit margin berpengaruh positif signifikan terhadap return on assets. Debt to assets ratio berpengaruh positif signifikan terhadap return on assets. Secara simultan juga kepemilikan institusional, net profit margin dan debt to assets ratio berpengaruh terhadap return on assets.

Implikasi yang dapat diberikan adalah prinsipal dapat meningkatkan kontrolnya terhadap agen agar laba perusahaan yang ditampilkan adalah laba yang sesungguhnya dan tidak ada manipulasi data yang dilakukan oleh pihak manapun. Selain itu perusahaan dapat berfokus pada peningkatan penjualan karena dapat 
meningkatkan laba yang signifikan. Kemudian perusahaan dapat berfokus pada peningkatan penggunaan aset yang pada masanya akan meningkatkan penjualan dan meningkatkan laba yang kemudian bisa digunakan perusahaan untuk melunasi utang-utangnya.

Saran

Bagi Peneliti Selanjutnya

a. Dapat menggunakan lebih banyak sampel dan lebih banyak sektor tidak hanya perusahaan yang terdaftar di LQ45.

b. Dapat menggunakan lebih banyak variabel.

Bagi Perusahaan

Peneliti berharap penelitian ini dapat dijadikan acuan bagi perusahaan untuk memerhatikan kepemilikan saham yang dimiliki perusahaannya dan juga memerhatikan jumlah penjualan serta utang yang dimiliki dari tahun ke tahun.

\section{Daftar Pustaka}

Anitasari, I. N. (2016). Pengaruh Debt to Asset Ratio, Operating Profit Margin, dan Net Profit Margin Terhadap Kinerja Keuangan Perusahaan Manufaktur Yang Terdaftar Di BEI Periode 2011-2014. Artikel Skripsi Universitas Nusantara PGRI Kediri.

Effendi, M. A. (2016). The Power of Good Corporate Governance: Teori dan Implementasi. Jakarta: Salemba Empat.

Epi, Y. (2017). Pengaruh Ukuran Perusahaan, Struktur Kepemilikan Manajerial dan Manajemen Laba Terhadap Kinerja Perusahaan Property dan Real Estate Yang Terdaftar Pada Bursa Efek Indonesia. Riset dan Jurnal Akunta, 1-2.

Fahmi, i. (2016). Pengantar Manajemen Keuangan Teori dan Soal Jawab. Bandung: Alfabeta.

Ghozali, I. (2016). Aplikasi Analisis Multivariete Dengan Program IBM SPSS 21. Diponogoro: Badan Penerbit Universitas Diponogoro.

Harlow. (2014). Financial Management Principles And Applications Titman Keown Martin Twelfth Edition. United States of America: Pearson.

Hery. (2014). Controllership : Manajemen Strategis, Pengendalian Internal. Jakarta: Gramedia Widiasarana.

Hery. (2017). Kajian Riset Akuntansi. Jakarta: Grasindo.

Husnan, S., \& Pudjiastuti, E. (2015). Dasar-Dasar Manajemen Keuangan. Yogyakarta: UPP STIM YKPN.

Kasmir. (2016). Pengantar Manajemen Keuangan. Jakarta: Prenadamedia Group.

Kurniawan, P., \& Budhi, M. K. (2017). Smart Leadership - Being A Decision Maker \#1. Yogyakarta: ANDI.

Rachman, R. A. (2014). Pengaruh Kepemilikan Manajerial dan Kepemilikan Institusional Terhadap Kinerja Keuangan Pada Perusahaan Manufaktur yang Terdaftar di Bursa Efek Indonesia. 4-5.

Siregar, S. (2015). Statistika Terapan Untuk Perguruan Tinggi. Jakarta: Prenadamedia Group.

Subagyo, Masruroh, N. A., \& Bastian, I. (2018). Akuntansi Manajemen Berbasis Desain. Yogyakarta: Gadjah Mada University Press. 
Suharyadi, \& S.K, P. (2016). Statistika untuk Ekonomi dan Keuangan Modern. Jakarta: Salemba Empat.

Sujarweni, V. W. (2015). Metodologi Penelitian Bisnis dan Ekonomi. Yogyakarta: PUSTAKABARUPRESS.

Sumarwan, U., Daryanto, A., Achsani, N. A., Fahmi, I., Nuryartono, N., Yoyo, T., et al. (2014). Metode Riset Bisnis dan Konsumen. Bogor: IPBPRESS.

Supriyono, R. (2018). Akuntansi Keprilakuan. Yogyakarta: Gadjah Mada University Press.

Sutrisno. (2017). Manajemen Keuangan Teori, Konsep dan Aplikasi. Yogyakarta: Ekonisia.

www.web.idx.co.id 